\title{
The possible role of heat shock protein-70 induction in collagen-induced arthritis in rats
}

\author{
MH El-Saka ${ }^{1}$, NM Madi ${ }^{1}$, A Shahba ${ }^{2}$ \\ ${ }^{1}$ Department of Physiology, Faculty of Medicine, Tanta University, Tanta, Egypt \\ ${ }^{2}$ Department of Internal Medicine, Faculty of Medicine, Tanta University, Tanta, Egypt \\ Received: November 25, 2018 \\ Accepted: May 6, 2019
}

\begin{abstract}
Aim: This study aimed to evaluate the possible role of heat shock protein-70 (HSP70) induction by 17-allylaminodemethoxygeldanamycin (17-AAG) in collagen-induced arthritis in rats. Material and methods: Male Wistar rats were divided into five groups ( $n=10$ /group) and were treated intraperitoneally twice a week for 4 weeks, namely normal control (saline), arthritis control (AR; saline), AR + 17-AAG, AR + methotrexate (MTX), and AR + 17-AAG + MTX. At the end of the treatments, arthritic score was determined and then the animals were sacrificed. Erythrocyte sedimentation rate (ESR), serum levels of HSP70, interleukin-17 (IL-17), tumor necrosis factor-alpha (TNF- $\alpha$ ), rheumatic factor (RF), C-reactive protein (CRP), malondialdehyde (MDA), glutathione peroxidase (GPx), and matrix metalloproteinase-9 (MMP-9) were determined. Results: In the AR group, all parameters increased significantly, except for GPx, which showed a pronounced decrease. The 17-AAG and/or MTX treatments significantly reduced arthritic score, ESR, IL-17, TNF- $\alpha$, RF, CRP, MDA, and MMP-9 with significant increase in GPx compared to the AR group. The HSP70 level was significantly higher in the $\mathrm{AR}+17-\mathrm{AAG}$ and the AR + 17-AAG + MTX groups but significantly lower in the AR + MTX group as compared to the AR group. Also, it was significantly lower in the AR + MTX group as compared to the AR+ 17-AAG group. Conclusion: We concluded that HSP70 induction by 17-AAG attenuated the inflammatory process in a rheumatoid arthritis (RA) model induced by collagen, which suggested that HSP70 inducers can be promising agents in the treatment of RA.
\end{abstract}

Keywords: heat shock protein-70, 17-AAG, collagen-induced arthritis, interleukin-17, methotrexate

\section{Introduction}

Rheumatoid arthritis (RA) is an autoimmune systemic disease with chronic inflammatory character that results in morbidity and mortality. It affects joints including cartilages, synovial membranes, and bone, resulting in bone erosion and cartilage degeneration with subsequent loss of functions of joints (10). Its etiology is poorly understood (16). Collagen-induced arthritis (CIA) is commonly used in experimental studies as it resembles RA in humans. CIA can be induced by injection of type-II collagen with subsequent development of severe polyarthritis in animals (11).

Methotrexate (MTX) is considered a standard antirheumatic drug due to its effectiveness in prolonged clinical use. Mechanisms of action of MTX might be explained by its antiinflammatory, cytostatic, immunosuppressive, and antiapoptotic effects $(22,34)$. In addition, MTX inhibits dihydrofolate reductase enzyme that is involved in purine synthesis, with

\footnotetext{
Corresponding author: Mervat H. El-Saka

Department of Physiology, Faculty of Medicine, Tanta University

Station/Tanta field, Gharbiya, Central Delta, Tanta 31511, Egypt

Phone: +200102312 6578; Fax: +20040 340 7734; E-mail: tantaphysiology@yahoo.com
} 
subsequent inhibition of de-novo synthesis of pyrimidine and purine (18). However, its administration is limited due to its toxic adverse effects as it can cause serious infections, cytopenia, ulceration of mucous membranes, and nausea (3). Hence, there is a need to use new antirheumatic drugs or develop a new strategy in the treatment of RA in combination with MTX.

Heat shock proteins (HSPs) constitute a chaperone-conserved protein family that plays important roles in refolding of protein misfolding under normal and stress conditions. The HSP70 is one of these HSPs induced from the cells in response to stress conditions, such as oxidative stress, infections, inflammation, exposure to heat stress, and ischemia-reperfusion (15). The HSP70 is also found in the bloodstream in patients who suffer from inflammatory or autoimmune diseases such as RA (39). It was proved to have a major role in suppressing autoimmune responses in some experimental models (4). The administration of HSP70 itself or HSP70-derived peptides has been reported in a few studies as a therapy for arthritis, both in vitro using cells of patients with RA or in animal models $(56,63)$.

The 17-allylaminodemethoxygeldanamycin (17-AAG) is a HSP70 co-inducer (17). It is a geldanamycin analog, which has antitumor effects via induction of apoptosis (59). Its mechanism of action might be due to its binding to heat shock protein-90 (HSP90), hence preventing conformational folding mediated by HSP90 and enhancing oncoprotein degradation; furthermore, it inhibits the binding of HSP90 with heat shock factor-1, with subsequent transcription of chaperones HSP70 (21).

The 17-AAG has favorable safety pharmacological use in experimental models, since previous studies showed that 17-AAG has lesser hepatotoxic effects than geldanamycin $(6,21,30,61)$, suggesting that the toxic effects may be avoided by applying small doses. The 17-AAG has also been used in the treatment of cancer in numerous experimental models (53). In addition, it has been proved that 17-AAG attenuated inflammation in models of brain injury (30) and other non-neurological experimental models of diseases, such as lung injury (8), uveitis (50), and atherosclerosis (27).

To our knowledge, there is no previous study evaluating the effect of 17-AAG in RA. Thus, this work proposed to examine the possible role of HSP70 induction by 17-AAG in CIA in rats. Furthermore, some hypotheses about its action and potential effects were investigated.

\section{Materials and Methods}

\section{Animals}

This study was conducted on 50 male Wistar rats. They were 10-12 weeks old, weighing 190-230 g. They were obtained from the animal house of Tanta University of Medical Sciences. The animals were housed in clean cages $(90 \mathrm{~cm}$ length $\times 62 \mathrm{~cm}$ width), five rats per cage, at suitable temperature $\left(23 \pm 2{ }^{\circ} \mathrm{C}\right)$ with 12-h light-dark cycle. The animals were allowed free access to food and water. The experimental protocol was approved by the ethical committee of the Faculty of Medicine, Tanta University (code approval number: 4320/04/30).

\section{Drug and chemicals}

Type-II collagen, incomplete Freund's adjuvant (IFA), and 17-AAG were obtained from Sigma Aldrich Co. (St. Louis, MO, USA). MTX was purchased from the United Co. 
(Cairo, Egypt) for distribution. Both 17-AAG and MTX were dissolved in saline. All kits that were used for measuring the studied parameters were obtained from Bio-Diagnostic Co. (Giza, Egypt).

\section{Experimental design}

The animals in all the experimental groups received all treatments intraperitoneally twice a week from the first day of the experiment for 4 weeks. They were randomly divided into five groups (10 rats per each group) as following:

1. Normal control group: rats received saline as a vehicle.

2. Arthritis control (AR) group: rats received saline as a vehicle. Arthritis was induced as described later.

3. Arthritis group treated with $17-\mathrm{AAG}(\mathrm{AR}+17-\mathrm{AAG})$ : rats received $17-\mathrm{AAG}$ in a dose of $5 \mathrm{mg} / \mathrm{kg}(21)$.

4. Arthritis group treated with $\operatorname{MTX}(\mathrm{AR}+\mathrm{MTX})$ : rats received MTX in a dose of $0.4 \mathrm{mg} / \mathrm{kg}(45)$.

5. Arthritis group treated with combination of 17-AAG and MTX (AR + 17-AAG + MTX): rats received 17-AAG in a dose of $5 \mathrm{mg} / \mathrm{kg}$ and MTX in a low dose of $0.2 \mathrm{mg} / \mathrm{kg}(33)$.

\section{Induction of arthritis}

Arthritis was induced in the rats according to the method of Karatas et al. (26) as following: the rats were anesthetized by phenobarbital sodium (15 mg/kg intraperitoneally) (44). Type-II collagen was dissolved in $0.01 \mathrm{M}$ acetic acid $(1 \mathrm{mg} / \mathrm{ml})$ and was emulsified in IFA at a 1:1 ratio. Then, they were injected intradermally into the tail in a dose of $(100 \mu \mathrm{g} / \mathrm{rat})$ and back paws in a dose of $(50 \mu \mathrm{g}$ in each paw $)$. After 1 week from the first injection of collagen, rats were injected again $(100 \mu \mathrm{g} / \mathrm{rat})$ into the tail. The onset of arthritis occurred after about 13-14 days from the first injection of collagen. Arthritis was confirmed when the arthritis score became more than 1 .

\section{Arthritic score}

The arthritis could be assessed by a macroscopic scoring for the four limbs. The score was ranged from 0 to 4 as described previously (7), as following:

Score $0=$ No swelling of the joints.

Score $1=$ Swelling and/or erythema of one joint.

Score $2=$ Swelling and/or erythema of two joints.

Score 3 = Swelling and/or erythema of three joints.

Score $4=$ Severe arthritis throughout the entire paw.

The affected joints might be included (interphalangeal, metacarpophalangeal, and radiocarpal joints) in forepaws and (interphalangeal, metatarsophalangeal, and tibiotarsal joints) in hind paws.

The severity of arthritis score for each animal was calculated by summing the individual paw scores (max: 16).

\section{Blood sampling and biochemical assay}

At the end of the experiment, after 4 weeks, the animals were sacrificed by cervical decapitation and blood samples were collected. Part of the fresh blood samples was used for determination of erythrocyte sedimentation rate (ESR) according to the method of Plebani 
and Piva (48). The rest of the blood was centrifuged at 3,000 cycles for $10 \mathrm{~min}$. The serum samples were separated and stored at $-80{ }^{\circ} \mathrm{C}$ for biochemical analysis of HSP70 using a quantitative enzyme-linked immunosorbent assay (ELISA) technique. The intra- and interassay coefficient of variation ranged between $4.5 \%$ and $7 \%$ (40). Interleukin-17 (IL-17) (1) and tumor necrosis factor-alpha (TNF- $\alpha$ ) were determined (49). In addition, rheumatic factor (RF) (42), C-reactive protein (CRP) (12), malondialdehyde (MDA) (5), glutathione peroxidase (GPx) (5), and matrix metalloproteinase-9 (MMP-9) (25) were determined using commercial ELISA kits. The procedures for all biochemical assays were performed as described in the product manuals. The results were estimated from the standard calibration curves on the internal standards.

\section{Statistical analysis}

The data were shown as mean \pm standard deviation. Data from the study were analyzed using one-way analysis of variance followed by Tukey's test to assess the significance. The $p$ values $<0.05$ were considered statistically significant. All the analyses were performed using SPSS for Windows (version 21.0; Chicago, IL, USA).

\section{Results}

\section{Arthritis score}

As shown in Fig. 1, arthritis was developed in the AR group as proved by high arthritic scores. As compared to the AR group, the arthritis score was significantly decreased in all AR-treated groups.

\section{HSP70, IL-17, and TNF- $\alpha$}

These were presented in Fig. 1. Compared to the control group, the serum level of HSP70 was significantly increased in the AR and all AR-treated groups. It was significantly higher in the $\mathrm{AR}+17-\mathrm{AAG}$ and the AR + 17-AAG + MTX groups but significantly lower in the AR + MTX group as compared to the AR group. In addition, it was significantly lower in the AR + MTX group as compared to the AR + 17-AAG group.

Regarding the serum levels of pro-inflammatory cytokines IL-17 and TNF- $\alpha$, they were significantly higher in the AR group as compared to the normal control group. Whereas in the AR-treated groups, the serum levels of these pro-inflammatory cytokines were significantly decreased as compared to the AR group. However, their levels were still significantly higher in all AR-treated groups as compared to the normal control, except for the level of IL-17 in the AR + 17-AAG + MTX group that returned to the normal value as compared to the normal control group.

\section{$E S R, R F$, and $C R P$}

As presented in Fig. 2, ESR, RF, and CRP were significantly increased in the AR group as compared to the normal control group. It was noticed that, as compared to the AR group, all these parameters were significantly decreased in the AR-treated groups. However, their levels were still significantly higher as compared to the normal control group. 

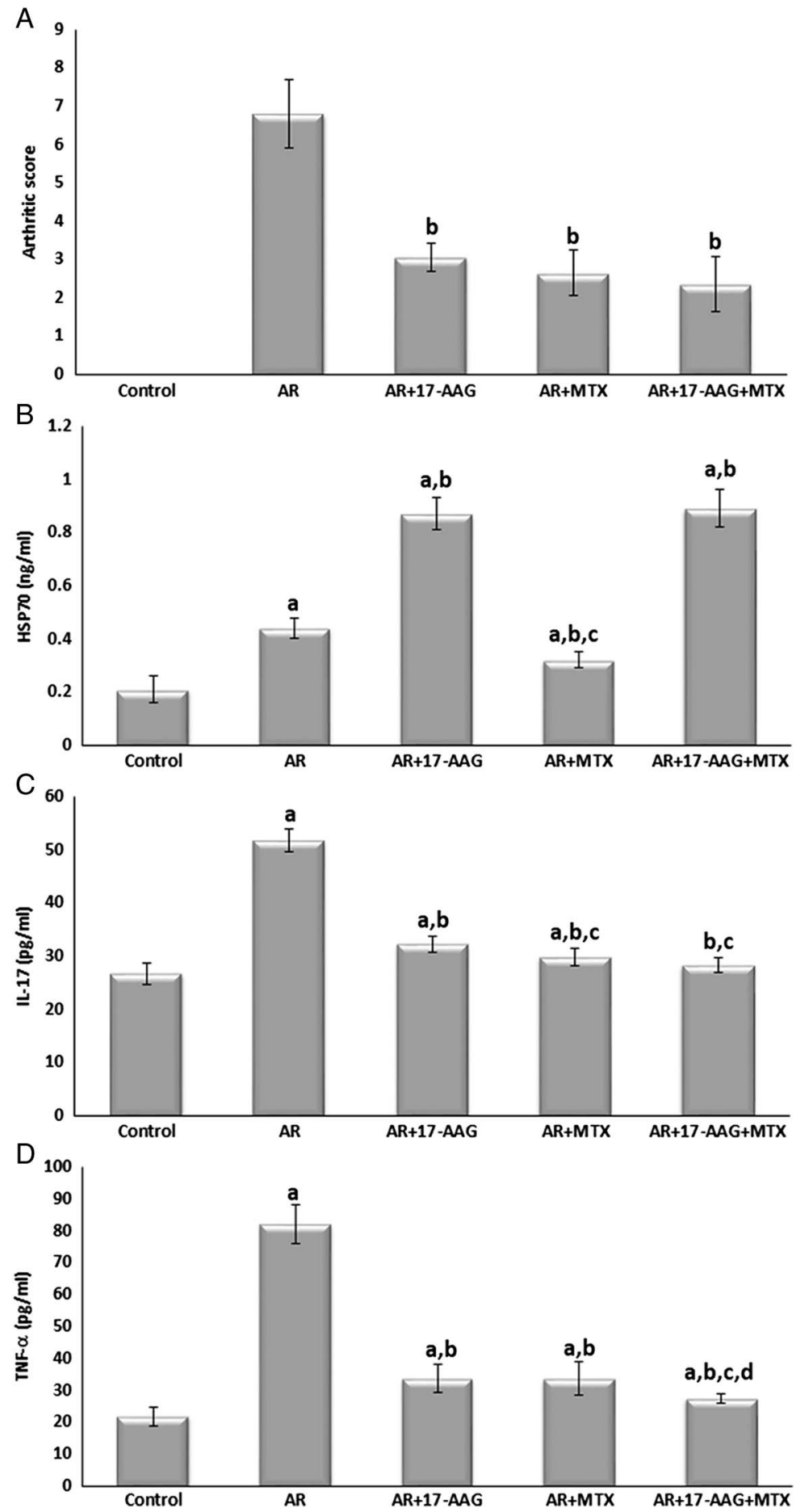

Fig. 1. Arthritis score, HSP70, IL-17, and TNF- $\alpha$ in all studied groups. Data are given as mean $\pm \mathrm{SD}$. ${ }^{\mathrm{a}} p<0.05$ vs. control group, ${ }^{\mathrm{b}} p<0.05$ vs. AR group, ${ }^{\mathrm{c}} p<0.05$ vs. AR + 17-AAG group, ${ }^{\mathrm{d}} p<0.05$ vs. $\mathrm{AR}+\mathrm{MTX}$ group 

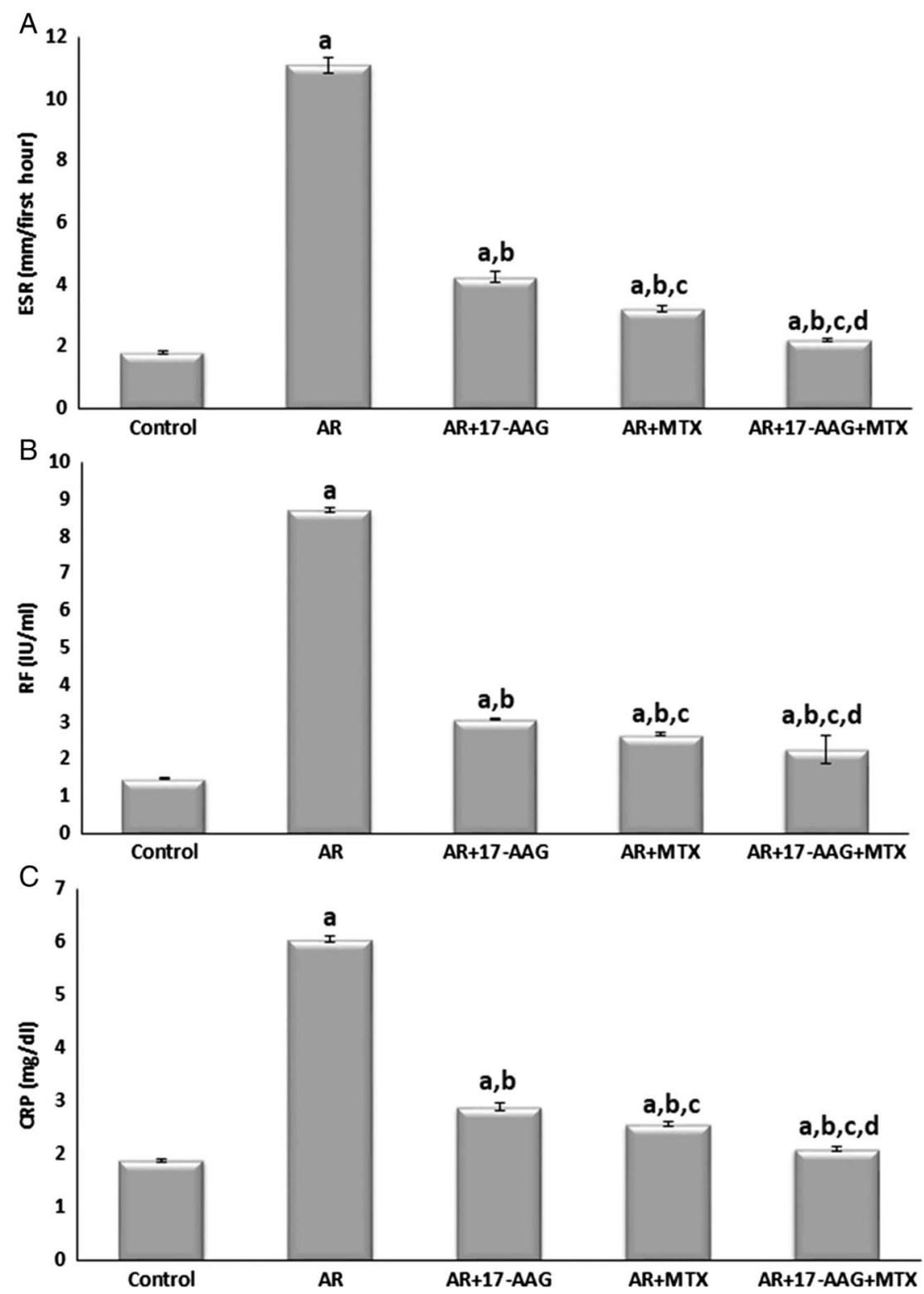

Fig. 2. ESR, RF, and CRP in all studied groups. Data are given as mean \pm SD. ${ }^{a} p<0.05$ vs. control group, ${ }^{\mathrm{b}} p<0.05$ vs. AR group, ${ }^{\mathrm{c}} p<0.05$ vs. AR $+17-\mathrm{AAG}$ group, ${ }^{\mathrm{d}} p<0.05$ vs. AR + MTX group

$M D A, G P x$, and MMP-9

Serum MDA and MMP-9 levels were significantly increased in the AR group with concomitant decrease in serum GPx level as compared to the normal control group (Fig. 3). In contrast, the MDA and MMP-9 levels were significantly decreased with concomitant increase in GPx level in the AR-treated groups compared to the AR group. The levels of GPx returned to normal control levels in the AR + MTX and the AR + 17-AAG + MTX groups (Fig. 3). 

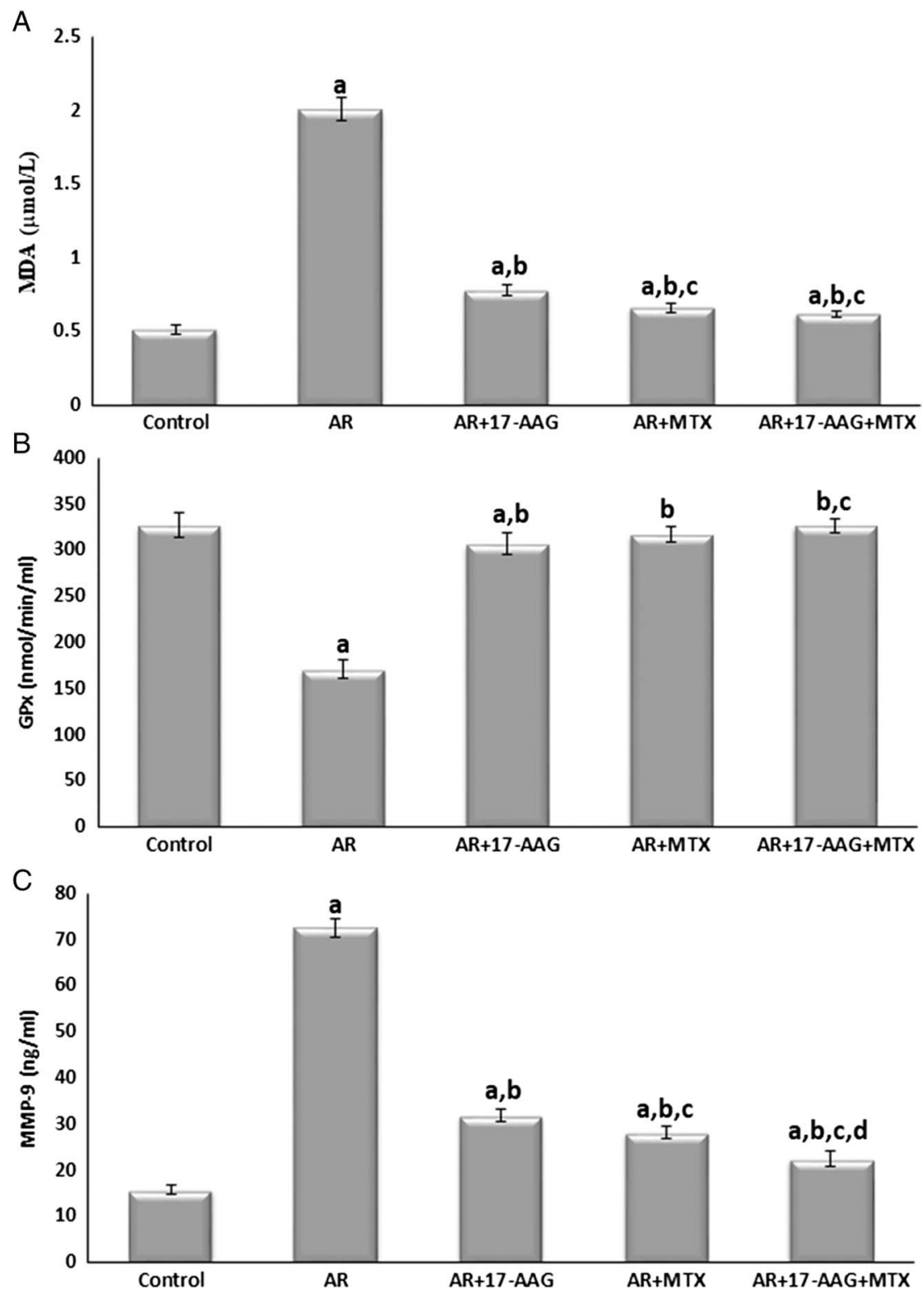

Fig. 3. MDA, GPx, and MMP-9 in all studied groups. Data are given as mean \pm SD. ${ }^{a} p<0.05$ vs. control group, ${ }^{\mathrm{b}} p<0.05$ vs. AR group, ${ }^{\mathrm{c}} p<0.05$ vs. AR $+17-\mathrm{AAG}$ group, ${ }^{\mathrm{d}} p<0.05$ vs. AR + MTX group

\section{Discussion}

This study revealed that HSP70 induction by 17-AAG attenuated the inflammatory conditions of RA induced by collagen injection. The results showed that the arthritic score and several inflammatory parameters increased significantly in the AR group, which were blunted by treatments with either 17-AAG and/or MTX. Furthermore, the serum level of HSP70 was 
significantly higher in the AR group as compared to the normal control group, and in the 17-AAG-treated groups compared to the other groups. In agreement with our results, Najafizadeh et al. (39) proved that HSP70 increased in patients with RA and it was correlated with the activity of RA. However, our results suggest that HSP70 induction by 17-AAG might be beneficial in the improvement of the inflammatory state in this arthritis model.

The IL-17, a cytokine synthesized by T-helper cells called Th-17 cells (64), contributes to the inflammatory process in the pathogenesis of RA, and its plasma level increases during the course of RA (35). It could stimulate the production of pro-inflammatory cytokines such as TNF- $\alpha$, IL-1, chemokines, and receptor activation of nuclear factor $\kappa \mathrm{B}(\mathrm{NF}-\kappa \mathrm{B})$ ligand (RANKL) protein in the synovial fluid. The IL-17 activates the macrophages and chondrocytes, which synthesize the destructive enzymes promoting erosion and destruction of joints (65). It also stimulates the release of destructive enzymes from the fibroblasts in the synovium (38). It has been reported that IL-17 activates the osteoclasts with subsequent bone resorption, in addition to production of nitric oxide and prostaglandin $\mathrm{E}_{2}$ that have been involved in destruction of cartilages (43). Thus, IL-17 injection in the joints of normal rats caused damage in joints (38). In this study, 17-AAG, MTX, and their combination significantly reduced serum IL-17 levels. In agreement with earlier results, MTX treatment reduced levels of IL-17 in RA $(19,36)$.

The reduction in the levels of IL-17 by 17-AAG might be due to induction of HSP70. This was in agreement with a previous study, which showed that HSP90 blockade was associated with HSP70 upregulation with subsequent inhibition of NF- $\kappa \mathrm{B}(60)$. The later is one of the major factors stimulating the proliferation of Th-17 cells, hence increasing IL-17 expression $(2,41)$. However, a research found that HSP70 expression in the cellular stress responses was associated with increased IL-17 expression (20). This was in agreement with results of this work, as in the AR group, both HSP70 and IL-17 levels were significantly elevated. Tissue damage and the elevated cytokine levels cause the release of HSP70 (62).

TNF- $\alpha$ is another pro-inflammatory mediator that has an important role in the pathogenesis of inflammatory diseases of the joints as well. Previous results have proved that drugs that inhibit TNF- $\alpha$ attenuate the inflammatory conditions (10). In this study, the levels of TNF- $\alpha$ increased in the AR group. This is in accordance with previous studies $(10,45)$, as the treatment with 17-AAG and/or MTX significantly reduced the serum level of TNF- $\alpha$, which suggested the anti-inflammatory effects of both drugs. In an in vitro study, HSP70 prevented the increase of the inflammatory cytokines induced by lipopolysaccharide (14). Furthermore, in an experimental stroke model in rats, overexpression of HSP70 inhibited the production of TNF- $\alpha$ (29).

In agreement with other previous results $(32,47,54)$, this study showed that serum levels of ESR, RF, and CRP were significantly increased in the AR group. It was noticed that these parameters were significantly lowered by $17-\mathrm{AAG}$ and/or MTX treatments.

It has been hypothesized that the rise of CRP levels might be due to the activation of macrophages, $\mathrm{B}$ and $\mathrm{T}$ lymphocytes, and the production of the inflammatory cytokines such as IL-6 and TNF- $\alpha$ that lead to the oxidative damage of vital organs such as the liver, with subsequent production of inflammatory mediators such as CRP (57). Also, TNF- $\alpha$ promotes the production of CRP in the liver via NF- $\kappa B$ with a subsequent rise in CRP level in the serum $(9,45)$, and CRP leads to activation of RANKL protein, which causes bone and joint destructions (28). It was demonstrated that 17-AAG has inhibited NF- $\kappa B$ nuclear translocation in the brain (51). Therefore, its anti-arthritic effects in this study could be due to the inhibition of NF- $\mathrm{KB}$ pathway with subsequent suppression of the production of the 
inflammatory mediators. Moreover, previous studies suggested that MTX inhibited NF- $\mathrm{kB}$ with subsequent abrogation of the inflammatory process in an RA model (58).

In this study, MDA level was significantly increased with concomitant significant decrease in GPx level in the AR group. These results are in accordance with previous studies in RA patients, which demonstrated high levels of MDA in the serum and synovial fluids with decreased antioxidant enzymes such as GPx (52).

Oxidative stress has been proved to play an important role in the pathogenesis of RA. Reactive oxygen radicals (e.g., hydrogen peroxide) produced by the inflammatory cells of the synovial fluid cause damage of the joints (23). Free radicals lead to damage of DNA structure, proteins, and lipids with subsequent lipid peroxidation (46). MDA is a product of lipid peroxidation; hence, it has been increased in RA diseases (13). The antioxidant enzymes, such as GPx, play an important role against free radicals (24), and the activity of this enzyme has been decreased in RA diseases (37).

The results of this study demonstrated that the serum level of MDA was significantly decreased with significant increase in GPx level by 17-AAG and/or MTX treatment, which suggested that both drugs have antioxidant effects.

Finally, the results of this study showed that the serum level of MMP-9 was significantly increased in AR as compared to the normal control. The treatment with 17-AAG and/or MTX significantly attenuated the increase in this enzyme. MMPs are enzymes that play a critical role in bone and cartilage destruction. It was suggested to be produced by macrophages. The IL-17 increased the production of MMP-9 from these cells (31). Also, 17-AAG reduced MMP-9 levels, which could be explained by inhibiting NF- $\mathrm{KB}$ signaling pathway (51).

In our experiment, the treatments started simultaneously as the arthritis was induced and continued about 2 weeks after the onset of arthritis. Therefore, the role of 17-AAG was suggested not only to be preventive but also therapeutic. Some previous studies started the treatments of RA during induction of arthritis $(45,55)$. Therefore, it is a limitation in this study that it could have been supplemented with experimental groups in which treatment would have been started after the onset of arthritis. Hence, this is recommended for further research.

\section{Conclusions}

We demonstrated that 17-AAG alone or in combination with a low dose of MTX attenuated the RA in CIA model by its anti-inflammatory and antioxidant effects, which might be due to the induction of HSP70. Therefore, we suggest that HSP70 co-inducers may be promising agents in the treatment of RA, or its combination with a low dose of MTX may have a therapeutic effect in the treatment of RA. However, further histopathological, behavioral, and molecular biological studies are required to reveal the effects of HSP70 inducers as therapeutic agents in RA on bone and cartilages of the joints and their mechanisms of actions.

\section{REFERENCES}

1. Abdallah M, Emam H, Attia E, Hussein J, Mohamed N: Estimation of serum level of interleukin-17 and interleukin-4 in leprosy, towards more understanding of leprosy immunopathogenesis. Indian J. Dermatol. Venereol. Leprol. 79(6), 772-776 (2013) 
2. Bae J, Munshi A, Li C, Samur M, Prabhala R, Mitsiades C, Anderson KC, Munshi NC: Heat shock protein 90 is critical for regulation of phenotype and functional activity of human T lymphocytes and NK cells. J. Immunol. 190(3), 1360-1371 (2013)

3. Bello AE, Perkins EL, Jay R, Efthimiou P: Recommendations for optimizing methotrexate treatment for patients with rheumatoid arthritis. Open Access Rheumatol. 9, 67-79 (2017)

4. Borges TJ, Wieten L, van Herwijnen MJ, Broere F, van der Zee R, Bonorino C, van Eden W: The anti-inflammatory mechanisms of Hsp70. Front. Immunol. 3, 95 (2012)

5. Casado A, Encarnacion Lopez-Fernandez M, Concepcion Casado M, de La Torre R: Lipid peroxidation and antioxidant enzyme activities in vascular and Alzheimer dementias. Neurochem. Res. 33(3), 450-458 (2008)

6. Chakraborty PK, Mustafi SB, Ganguly S, Chatterjee M, Raha S: Resveratrol induces apoptosis in K562 (chronic myelogenous leukemia) cells by targeting a key survival protein, heat shock protein 70. Cancer Sci. 99(6), 1109-1116 (2008)

7. Chang Y, Jia X, Wei F, Wang C, Sun X, Xu S, Yang X, Zhao Y, Chen J, Wu H, Zhang L, Wei W: CP-25, a novel compound, protects against autoimmune arthritis by modulating immune mediators of inflammation and bone damage. Sci. Rep. 6, 26239 (2016)

8. Chatterjee A, Dimitropoulou C, Drakopanayiotakis F, Antonova G, Snead C, Cannon J, Venema RC, Catravas JD: Heat shock protein 90 inhibitors prolong survival, attenuate inflammation, and reduce lung injury in murine sepsis. Am. J. Respir. Crit. Care Med. 176(7), 667-675 (2007)

9. Chen L, Deng H, Cui H, Fang J, Zuo Z, Deng J, Li Y, Wang X, Zhao L: Inflammatory responses and inflammation-associated diseases in organs. Oncotarget. 9(6), 7204-7218 (2017)

10. Chimenti MS, Triggianese P, Conigliaro P, Candi E, Melino G, Perricone R: The interplay between inflammation and metabolism in rheumatoid arthritis. Cell Death Dis. 6, e1887 (2015)

11. Choudhary N, Bhatt LK, Prabhavalkar KS: Experimental animal models for rheumatoid arthritis. Immunopharmacol. Immunotoxicol. 40(3), 193-200 (2018)

12. de Beer FC, Baltz ML, Munn EA, Feinstein A, Taylor J, Bruton C, Clamp JR, Pepys MB: Isolation and characterization of $\mathrm{C}$-reactive protein and serum amyloid $\mathrm{P}$ component in the rat. Immunology 45(1), 55-70 (1982)

13. Desai PB, Manjunath S, Kadi S, Chetana K, Vanishree J: Oxidative stress and enzymatic antioxidant status in rheumatoid arthritis: a case control study. Eur. Rev. Med. Pharmacol. Sci. 14(11), 959-967 (2010)

14. Dokladny K, Lobb R, Wharton W, Ma TY, Moseley PL: LPS-induced cytokine levels are repressed by elevated expression of HSP70 in rats: possible role of NF-kappaB. Cell Stress Chaperones 15(2), 153-163 (2010)

15. Duncan EJ, Cheetham ME, Chapple JP, van der Spuy J: The role of HSP70 and its co-chaperones in protein misfolding, aggregation and disease. Subcell. Biochem. 78, 243-273 (2015)

16. Entezami P, Fox DA, Clapham PJ, Chung KC: Historical perspective on the etiology of rheumatoid arthritis. Hand Clin. 27(1), 1-10 (2011)

17. Gu Y, Chen J, Wang T, Zhou C, Liu Z, Ma L: Hsp70 inducer, 17-allylamino-demethoxygeldanamycin, provides neuroprotection via anti-inflammatory effects in a rat model of traumatic brain injury. Exp. Ther. Med. 12(6), 3767-3772 (2016)

18. Hagner N, Joerger M: Cancer chemotherapy: targeting folic acid synthesis. Cancer Manag. Res. 2, 293-301 (2010)

19. Halilova KI, Brown EE, Morgan SL, Bridges SL, Hwang MH, Arnett DK, Danila MI: Markers of treatment response to methotrexate in rheumatoid arthritis: where do we stand? Int. J. Rheumatol. 2012, 978396 (2012)

20. He Z, Sun X, Ma Z, Fu J, Huang B, Liu F, Chen Y, Deng T, Han X, Sun D, Lan C: Heat shock protein 70 protects mouse against post infection irritable bowel syndreome via up regulating intestinal $\gamma \delta$ T cell's Th17 response. Cell Biosci. 8, 38 (2018)

21. Ho SW, Tsui YT, Wong TT, Cheung SK, Goggins WB, Yi LM, Cheng KK, Baum L: Effects of 17-allylamino-17-demethoxygeldanamycin (17-AAG) in transgenic mouse models of frontotemporal lobar degeneration and Alzheimer's disease. Transl. Neurodegener. 2(1), 24 (2013)

22. Huang WY, Yang PM, Chang YF, Marquez VE, Chen CC: Methotrexate induces apoptosis through p53/p21-dependent pathway and increases E-cadherin expression through downregulation of HDAC/EZH2. Biochem. Pharmacol. 81, 510-517 (2011)

23. Ishibashi T: Molecular hydrogen: new antioxidant and anti-inflammatory therapy for rheumatoid arthritis and related diseases. Curr. Pharm. Des. 19(35), 6375-6381 (2013)

24. Iskusnykh IY, Popova TN, Agarkov AA, Pinheiro de Carvalho MA, Rjevskiy SG: Expression of glutathione peroxidase and glutathione reductase and level of free radical processes under toxic hepatitis in rats. J. Toxicol. 2013, 870628 (2013) 
25. Jumper C, Cobos E, Lox C: Determination of the serum matrix metalloproteinase-9 (MMP-9) and tissue inhibitor of matrix metalloproteinase-1 (TIMP-1) in patients with either advanced small-cell lung cancer or non-small-cell lung cancer prior to treatment. Respir. Med. 98(2), 173-177 (2004)

26. Karatas A, Koca SS, Ozgen M, Dagli AF, Erman F, Sahin N, Sahin K, Isik A: Pemetrexed ameliorates experimental arthritis in rats. Inflammation 38(1), 9-15 (2015)

27. Kim J, Jang SW, Park E, Oh M, Park S, Ko J: The role of heat shock protein 90 in migration and proliferation of vascular smooth muscle cells in the development of atherosclerosis. J. Mol. Cell. Cardiol. 72, 157-167 (2014)

28. Kim KW, Kim BM, Moon HW, Lee SH, Kim HR: Role of C-reactive protein in osteoclastogenesis in rheumatoid arthritis. Arthritis Res. Ther. 17, 41 (2015)

29. Kim N, Kim JY, Yenari MA: Anti-inflammatory properties and pharmacological induction of Hsp70 after brain injury. Inflammopharmacology 20(3), 177-185 (2012)

30. Kim N, Kim JY, Yenari MA: Pharmacological induction of the 70-kDa heat shock protein protects against brain injury. Neuroscience 284, 912-919 (2015)

31. Klein T, Bischoff R: Physiology and pathophysiology of matrix metalloproteases. Amino Acids 41(2), 271-290 (2011)

32. Kotulska A, Kopec-Medrek M, Grosicka A, Kubicka M, Kucharz EJ: Correlation between erythrocyte sedimentation rate and C-reactive protein level in patients with rheumatic diseases. Reumatologia 53(5), 243-246 (2015)

33. Koyama A, Tanaka A, To H: Daily oral administration of low-dose methotrexate has greater antirheumatic effects in collagen-induced arthritis rats. J. Pharm. Pharmacol. 69(9), 1145-1154 (2017)

34. Kozub P, Simaljakova M: Systemic therapy of psoriasis: methotrexate. Bratisl. Lek. Listy. 112, 390-394 (2011)

35. Kuwabara T, Ishikawa F, Kondo M, Kakiuchi T: The role of IL-17 and related cytokines in inflammatory autoimmune diseases. Mediators Inflamm. 2017, 3908061 (2017)

36. Li Y, Jiang L, Zhang S, Yin L, Ma L, He D, Shen J: Methotrexate attenuates the Th17/IL-17 levels in peripheral blood mononuclear cells from healthy individuals and RA patients. Rheumatol. Int. 32(8), 2415-2422 (2012)

37. Mateen S, Moin S, Khan AQ, Zafar A, Fatima N: Increased reactive oxygen species formation and oxidative stress in rheumatoid arthritis. PLoS One 11(4), e0152925 (2016)

38. Miossec P: Update on interleukin-17: a role in the pathogenesis of inflammatory arthritis and implication for clinical practice. RMD Open 3(1), e000284 (2017)

39. Najafizadeh SR, Ghazizadeh Z, Nargesi AA, Mahdavi M, Abtahi S, Mirmiranpour H, Nakhjavani M: Analysis of serum heat shock protein 70 (HSPA1A) concentrations for diagnosis and disease activity monitoring in patients with rheumatoid arthritis. Cell Stress Chaperones. 20(3), 537-543 (2015)

40. Njemini R, Demanet C, Mets T: Comparison of two ELISAs for the determination of Hsp70 in serum. J. Immunol. Methods. 306(1-2), 176-182 (2005)

41. Oh H, Ghosh S: NF-кB: roles and regulation in different CD4(+) T-cell subsets. Immunol. Rev. 252(1), 41-51 (2013)

42. Oka H, Hirohata S, Inoue T, Iwamoto S, Miyamoto T: Quantitative determination of IgM-rheumatoid factor by enzyme immunoassay-standardization using a serum from a rheumatoid arthritis patient. Clin. Chim. Acta. 188(2), 147-159 (1990)

43. Onishi RM, Gaffen SL: Interleukin-17 and its target genes: mechanisms of interleukin-17 function in disease. Immunology 129(3), 311-321 (2010)

44. Pantaleao TU, Mousovich F, Rosenthal D, Padron AS, Carvalho DP, Da Costa VM: Effect of serum estradiol and leptin levels on thyroid function, food intake and body weight gain in female Wistar rats. Steroids 75(10), 638-642 (2010)

45. Paskova L, Kuncirova V, Ponist S, Mihalova D, Nosal R, Harmatha J, Hradkova I, Cavojsky T, Bilka F, Siskova K, Paulikova I, Bezakova L, Bauerova K: Effect of N-feruloylserotonin and methotrexate on severity of experimental arthritis and on messenger RNA expression of key proinflammatory markers in liver. J. Immunol. Res. 2016, 7509653 (2016)

46. Phaniendra A, Jestadi DB, Periyasamy L: Free radicals: properties, sources, targets, and their implication in various diseases. Indian J. Clin. Biochem. 30(1), 11-26 (2015)

47. Pincus T, Gibson KA, Shmerling RH: An evidence-based approach to laboratory tests in usual care of patients with rheumatoid arthritis. Clin. Exp. Rheumatol. 32(5 Suppl. 85), S-23-S-28 (2014)

48. Plebani M, Piva E: Erythrocyte sedimentation rate: use of fresh blood for quality control. Am. J. Clin. Pathol. 117(4), 621-626 (2002)

49. Pleyer U, Milani JK, Ruckert D, Rieck P, Mondino BJ: Determinations of serum tumor necrosis factor alpha in corneal allografts. Ocul. Immunol. Inflamm. 5(3), 149-155 (1997) 
50. Poulaki V, Iliaki E, Mitsiades N, Mitsiades CS, Paulus YN, Bula DV, Gragoudas ES, Miller JW: Inhibition of Hsp90 attenuates inflammation in endotoxin-induced uveitis. FASEB J. 21(9), 2113-2123 (2007)

51. Qi J, Liu Y, Yang P, Chen T, Liu XZ, Yin Y, Zhang J, Wang F: Heat shock protein 90 inhibition by 17-dimethylaminoethylamino-17-demethoxygeldanamycin protects blood-brain barrier integrity in cerebral ischemic stroke. Am. J. Transl. Res. 7(10), 1826-1837 (2015)

52. Quinonez-Flores CM, Gonzalez-Chavez SA, Del Rio Najera D, Pacheco-Tena C: Oxidative stress relevance in the pathogenesis of the rheumatoid arthritis: a systematic review. Biomed Res. Int. 2016, 6097417 (2016)

53. Schaefer S, Svenstrup TH, Guerra B: The small-molecule kinase inhibitor D11 counteracts 17-AAG-mediated up-regulation of HSP70 in brain cancer cells. PLoS One 12(5), e0177706 (2017)

54. Shen C, Sun XG, Liu N, Mu Y, Hong CC, Wei W, Zheng F: Increased serum amyloid A and its association with autoantibodies, acute phase reactants and disease activity in patients with rheumatoid arthritis. Mol. Med. Rep. 11(2), 1528-1534 (2015)

55. Slovak L, Svik K, Mihalova D, Toth J, Czigle S, Paskova L, Bilka F, Bauerova K: Ferulaldehyde improves the effect of methotrexate in experimental arthritis. Molecules 22(11), E1911 (2017)

56. Spierings J, van Eden W: Heat shock proteins and their immunomodulatory role in inflammatory arthritis. Rheumatology (Oxford) 56(2), 198-208 (2017)

57. Sproston NR, Ashworth JJ: Role of C-reactive protein at sites of inflammation and infection. Front. Immunol. 9 , 754 (2018)

58. Spurlock CF, Gass HM, Bryant CJ, Wells BC, Olsen NJ, Aune TM: Methotrexate-mediated inhibition of nuclear factor $\mathrm{\kappa B}$ activation by distinct pathways in $\mathrm{T}$ cells and fibroblast-like synoviocytes. Rheumatology (Oxford) 54(1), 178-187 (2015)

59. Sugimoto K, Sasaki M, Isobe Y, Tsutsui M, Suto H, Ando J, Tamayose K, Ando M, Oshimi K: Hsp90-inhibitor geldanamycin abrogates G2 arrest in p53-negative leukemia cell lines through the depletion of Chk1. Oncogene 27(22), 3091-3101 (2008)

60. Tukaj S, Zillikens D, Kasperkiewicz M: Inhibitory effects of heat shock protein 90 blockade on proinflammatory human Th1 and Th17 cell subpopulations. J. Inflamm. (Lond.) 11(1), 10 (2014)

61. Vaishampayan UN, Burger AM, Sausville EA, Heilbrun LK, Li J, Horiba MN, Egorin MJ, Ivy P, Pacey S, Lorusso PM: Safety, efficacy, pharmacokinetics, and pharmacodynamics of the combination of sorafenib and tanespimycin. Clin. Cancer Res. 16(14), 3795-3804 (2010)

62. van Eden W: Immune tolerance therapies for autoimmune diseases based on heat shock protein T-cell epitopes. Philos. Trans. R. Soc. Lond. B Biol. Sci. 373, 1738 (2018)

63. Wieten L, van der Zee R, Spiering R, Wagenaar-Hilbers J, van Kooten P, Broere F, van Eden W: A novel heatshock protein co-inducer boosts stress protein $\mathrm{Hsp} 70$ to activate $\mathrm{T}$ cell regulation of inflammation in autoimmune arthritis. Arthritis Rheum. 62(4), 1026-1035 (2010)

64. Ye L, Jiang B, Deng J, Du J, Xiong W, Guan Y, Wen Z, Huang K, Huang Z: IL-37 alleviates rheumatoid arthritis by suppressing IL-17 and IL-17-triggering cytokine production and limiting Th17 cell proliferation. J. Immunol. 194(11), 5110-5119 (2015)

65. Zenobia C, Hajishengallis G: Basic biology and role of interleukin-17 in immunity and inflammation. Periodontol. 2000 69(1), 142-159 (2015) 